\title{
1
}

\section{How to Use This Book}

The main part of this book consists of a series of medieval texts presented in both their original forms and in translation, based on episodes highlighted in The Silmarillion, The Hobbit, and The Lord of the Rings. Whilst this does not represent the full corpus of Professor Tolkien's fiction, other works are referenced throughout the book.

The first port of call, however, is a discussion of Tolkien's career as a medievalist (2.1.3-5). This gives essential background material and should be read before progressing further. Newcomers to the field of medieval studies should then read through the introductory guides to Old English, Old Norse, Middle English, Celtic, Finnish, and medieval languages overall to get a bearing on the historical and linguistic context of the texts presented later (2.2). The essays on the quest, epic literature, runes, names, alliterative verse, and the relationship between Middleearth and the real Middle Ages are presented as examples of major themes and similarities between Tolkien's writing and those found in medieval literature. These give an overview of these subjects with reference to general parallels in Tolkien's work and will be of particular use to those wishing to study medieval language and literature further.

The texts themselves are designed to be read in the order they appear in the book, and, to avoid repetition, some cross-referencing to earlier texts occurs. When reading the texts, those who are new to medieval literature are advised to look at the summary which precedes each entry to understand the link to The Silmarillion, The Hobbit, and The Lord of the Rings; to read briefly the information about the text; but mainly to concentrate on the discussion, where parallels with Tolkien's fiction are explored. Such readers are also advised to work mainly with the translations, whilst looking at the original texts on the facing page to see if any patterns or similarities emerge - for example, recurring words or phrases. Readers more familiar with medieval literature will find that the notes to each text provide more in-depth information about language and manuscripts as well as further discussion of Tolkien's own views of the text. 